\title{
A CONSTRUÇÃO DE UMA NOVA ÉTICA SEGUNDO O DISCURSO DA MODERNIDADE REFLEXIVA E GLOBALIZADA
}

\author{
THE CONSTRUCTION OF A NEW ETHICS ACCORDING TO THE \\ DISCOURSE OF REFLECTIVE AND GLOBALIZED MODERNITY
}

\author{
Irene Portella ${ }^{1}$ \\ Maria Carolina Carvalho de Almendra Freitas ${ }^{2}$ \\ Francelise Camargo de Lima $^{3}$
}

\section{RESUMO}

A modernidade chegou e sempre outra estará por vir e diante dos avanços tecnológicos e das modernas técnicas de propagação da informação e dados a sociedade ampliou sua forma de interação. As importantes mudanças que o mundo econômico, social e jurídico está percebendo trouxe a necessidade de adequação cultural, moral. Em consequência isso implica dizer que ética precisa ser repensada no mesmo compasso que o agir humana se apresenta de forma diversa que em outras eras apresentou. Nessa nova era de direitos, exigir efetividade na sua observação e consequente prática alcançando o que de fato busca que é o bem estar social.

\section{Palavras-chaves: Ética, Modernidade, Globalização.}

\begin{abstract}
A modernity has arrived and always another is yet to come and in the face of technological advances and modern techniques for the propagation of information and data in society, expanded its form of interaction. As important changes in the economic, social and legal world are perceived, it brought a need for cultural, moral adequacy. As a consequence, this implies saying that ethics needs to be compensated to the same extent as the human act, if presented in a different or different way. In this new era of rights, demand effectiveness in its observation and consequent practice to reach or discover facts that are actually social.
\end{abstract}

\footnotetext{
${ }^{1}$ Doutora em Direito Constitucional pelo departamento de Direito Público e Teoria do Estado, pela Universidade de Santiago de Compostela.

${ }^{2}$ Graduação em direito pelo Centro de Ensino Unificado de Teresina - CEU; especialização em direito público e em direito privado pela universidade Federal do Piaú - UFPI, Mestrado em Direito Internacional e Econômico pela Universidade Católica De Brasília - UCB; Doutoranda em Direito Político e Econômico do programa de pós-graduação stricto sensu da Universidade Presbiteriana Mackenzie - UPM.

${ }^{3}$ Doutoranda e Mestre em Direito Empresarial e Cidadania pelo Centro Universitário Curitiba.
} 
Keywords: Ethics, Modernity, Globalization.

\section{INTRODUÇÃO}

O tema central da pesquisa possui a finalidade de evidenciar a influência da ética nas relações humanas e de que forma a ética interage com a moral, a tradição, a ciência e aos princípios constitucionais que compõe o conceito de cidadania. Os ideais do direito pátrio é a liberdade, a justiça e a solidariedade e nesse viés investigará se a ética contribui.

Em um primeiro momento abordar-se-á os conceitos sobre ética e sua interação com os demais ramos da ciência transcrevendo sua importância nas relações humanas e sua importância como elemento transformador.

Em seguida demonstrar-se-á a gradual expansão da modernidade e da ética em um diálogo apto a apresentar que a ética é essencial para um convívio harmônico em uma sociedade cada vez mais complexa.

Em continuidade a proposta de estudo, que segue demonstrando de que forma o sucesso de uma modernidade, em medida que a mesma se apresenta complexa, pode influenciar diretamente na transformação do significado da ética ao ponto de causar conflito quanto a sua aplicabilidade e a necessidade emergente ressignificação da ética a partir dos signos tradicionais adequando-se a nova interação humana.

Diante do exposto, o estudo bibliográfico, estando ciente da necessidade de reflexão sobre a atuação humana e seu poder transformador, se propõem a responder em que medida a modernidade global clama por uma nova ética?

\section{CONSIDERAÇÕES IMPORTANTES SOBRE A ÉTICA}

O significado da palavra "Ética" deriva da palavra grega chamada ethos, da análise de sua essência conclui-se que seu significado é a conduta a partir de uma consciência própria, individual que reflete inequivocamente na coletividade. A partir da análise dos reflexos e consequências do comportamento individual, o homem busca distinguir o bem e o mal de tal forma que as ações humanas serão orientadas no caminho do bem.

A ética é um objeto de estudo da filosofia que se preocupa com a relação humana perante as normas resultantes das reflexões individuais e coletivas. Sua essência pode ser 
definida como o conjunto de valores morais que direcionam o agir humano na busca da justiça social.

Quando o assunto é a ética logo surge o questionamento sobre se ética e moral possuem o mesmo significado. Ocorre que a moral é constituída por normas que representam certos valores culturais em específico e a ética é mais ampla e universal por contemplar o agir virtuoso do homem.

Comte-Sponville afirma que:

“ [...] a moral é um conjunto de coisas a que um indivíduo se obriga ou que proíbe a si mesmo, não para aumentar a sua felicidade ou o seu bem-estar, o que não passaria de egoísmo, mas para levar em conta os interesses ou os direitos do outro, para não ser um malvado, para permanecer fiel a uma certa ideia de humanidade e de si.".

Os conceitos de ética e moral muitas vezes são confundidos contudo são distintos, a ética contempla a moral, mas possui um significado mais abrangente senão vejamos a lição de Cortella que diz ser "a ética é o que marca a fronteira da nossa convivência. [...] é aquela perspectiva para olharmos os nossos princípios e os nossos valores para existirmos juntos" ${ }^{\prime 4}$ ou seja, corresponde aos princípios e valores que orientam a conduta humana no convívio em sociedade.

Chauí é enfático ao afirmar que "a Filosofia existe há vinte e cinco séculos e, neste período, a ética, enquanto um dos seus principais ramos, esteve sempre presente e continua viva"5 sendo possível concluir que a ética alimenta a tradição dos valores reconhecidos como essenciais a boa e pacífica interação entre os indivíduos e é a razão pela qual muitos filósofos e pensadores se propuseram estudar e delimitar sua área de abrangência.

A Ética para Sócrates conforme a lição de Vázquez significa " bondade, conhecimento e felicidade que se entrelaçam estreitamente. $\mathrm{O}$ homem age retamente quando conhece o bem e, conhecendo-o não pode deixar de praticá-lo; por outro lado, aspirando ao bem, sente-se dono de si mesmo e, por conseguinte, é feliz."6

\footnotetext{
${ }^{4}$ CORTELLA, M. S. Qual é a tua obra? Inquietações, propositivas sobre gestão, liderança e ética. Petrópolis: Vozes, 2009. p. 102

${ }^{5}$ CHAUÍ, M. Convite à Filosofia. São Paulo: Ática, 1998.

6 VÁZQUES, Adolfo Sánchez. Ética. Civilização Brasileira, 15 ed., 1997.p.231.
} 
Em continuidade ao pensamento filosófico de Sócrates, seu discípulo e admirador Platão, em sua obra chamada As Leis, descreveu que os homens são bons "quando são capazes de dominar-se, e os maus são aqueles que não são capazes de fazê-lo"7.

Platão desenvolveu uma teoria racional sobre a constituição da alma humana que julgava ser eterna estabelecendo a supremacia e autonomia da razão sobre as emoções e os impulsos ou a vontade". 8

Aristóteles sistematizou a ética afirmando que há uma tendência natural para que tudo de uma forma ou outra manifestam-se para o bem e acredita "os homens tornam-se arquitetos construtores e tocadores de lira tangendo seus instrumentos. Da mesma forma, tornamo-nos justos praticando atos justos"9

Acquaviva conceitua ética com a observação do comportamento humano a distinguir erros e desvios aptos a formular princípios essenciais que regram a conduta do homem a partir de valores genéricos e estáveis, a Ética é ajustável a cada época e circunstância. ${ }^{10}$

Atualmente a ética é definida como ramo da Filosofia que estuda o comportamento moral e relaciona a moral como uma prática, entendida por Cortella (2009, p. 103) como o "exercício das condutas". ${ }^{11}$ A ética pode ser conceituada como característica valorosa de um comportamento humano a partir da observação das regras morais no comportamento social.

Chauí define que ética "não se trata, pois, rigorosamente de uma ciência, mas de uma reflexão em busca de uma fundamentação teórica e crítica dos nossos conhecimentos e de nossas práticas". ${ }^{12}$

Sobre este conceito Matos nos expõe:

“Temos uma natureza em devir. O ser humano é, ao mesmo tempo, um ser
atualmente advindo e um ser ainda a vir, apenas prometido a si mesmo. (...) É
aqui que se manifesta a estrutura fundamental da ação: de um lado, ela é aquilo
em que se tornou, aquilo que ela é agora: do outro, também é uma antecipação
de seu ser realizado e, por ser ação de um agente autônomo, ela implica em si
a responsabilidade daquilo que fazemos de nós mesmos. E veremos como a

7 PLATÃO, As Leis, 644b.

8 GOUVÊA, Ricardo Quadros. Ética e Cidadania: A busca humana por valores solidários. In: Um olhar sobre a ética. São Paulo: Editora Mackenzie, 2002. p. 15.

${ }^{9}$ ARISTÓTELES, Ética a Nicômaco. Pietro Nassetti (tradução). Martin Claret, SP, 2007.

${ }^{10}$ ACQUAVIVA, Marcus Cláudio. Notas Introdutórias à Ética Jurídica. São Paulo: Desafio Cultural, 2002.p. 27

${ }^{11}$ CORTELLA. op. cit., p. 103

${ }^{12}$ CHAUÍ, . op. cit. 
responsabilidade de cada ser humano para consigo mesmo constitui, ao mesmo tempo, uma responsabilidade que ele tem com todos os homens". ${ }^{13}$

A ética e a ciência se encontram na busca pela verdade, enquanto a ética é voltada para as ações humanas no intuito de promover a realização dos objetivos das pessoas, a ciência investiga todos os fenômenos de interesse humano o que é enfatizado pelo pensamento de Lucca citando Adeodato como sendo:

“(...) parte da filosofia responsável pela investigação dos princípios que motivam, distorce, disciplinam ou orientam o comportamento humano, refletindo especialmente a respeito da essência das normas, valores, prescrições e exortações presentes em qualquer realidade social."14

Assim, é possível afirmar que a ética é um exercício de constante reflexão e busca pelo aprimoramento da conduta humana. E na medida em que o homem revisa seus valores, sua moral, e suas práticas aprimora seu poder de transformar o mundo criando normas que direcionam um comportamento responsável para o convívio pacifico em sociedade.

O ser humano é um ser social, não vive por si só, estabelece relacionamentos entre seus pares em todas as subdivisões da vida. Vive em família, em comunidade, em grupos escolares e de trabalho, enfim são inúmeras as relações que estabelece ao longo de sua existência, mas ainda sim, preserva sua singularidade individual.

O homem em sua perspectiva individual é senhor de suas vontades e ideais, e a partir de sua cultura e valores pode expressar-se de forma singular e é nesse contexto que surge a ética para condicionar a expressão máxima da individualidade ao bem estar comum possibilitando o convívio pacífico e harmonioso como garantia da dignidade humana.

É notória a semelhança entre moral e ética, é verdade que possuem significados muito parecidos, mas não são iguais, enquanto a primeira a partir de valores e costumes estipula um determinado regramento do agir a segunda é a constante e profunda reflexão sobre o comportamento, sinalizando a melhor e mais adequada ação à luz do bem tornando o homem responsável pelos seus atos.

A responsabilidade pode ser conceituada partindo de seu original significado que segundo a lição de Stoco:

\footnotetext{
${ }^{13}$ MATOS, O. C. F. A escola de Frankfurt: luzes e sombras do iluminismo. São Paulo: Editora Moderna, 1993

${ }^{14}$ LUCCA, Newton De, Da ética Geral à ética Empresarial, São Paulo: Quartier Latin, 2009.
} 


\begin{abstract}
“A noção da responsabilidade pode ser haurida da própria origem da palavra, que vem do latim respondere, responder a alguma coisa, ou seja, a necessidade que existe de responsabilizar alguém pelos seus atos danosos. Essa imposição estabelecida pelo meio social regrado, através dos integrantes da sociedade humana, de impor a todos o dever de responder por seus atos, traduz a própria noção de justiça existente no grupo social estratificado. Revela-se, pois, como algo inarredável da natureza humana". ${ }^{15}$
\end{abstract}

A responsabilidade recairá sobre alguém devido ao fato de que o mesmo é capaz de pensar e refletir sobre os seus atos antes de agir e essa condição de livre arbítrio corresponde a liberdade. Há uma grande discussão no campo da filosofia sobre o que vem a ser exatamente a liberdade humana, mesmo assim a liberdade pode ser conceituada como um poder inerente ao homem do exercício de suas vontades respeitando os limites impostos pela lei.

A filosofia, por meio de seus renomados filósofos descrevem a liberdade de formas diversas, por exemplo para Descartes a liberdade é decisão e assim se manifesta seu pensamento: "para que eu seja livre, não é necessário que eu seja indiferente na escolha de um ou outro dos dois contrários; mas, antes, quanto mais eu tender para um, seja porque eu conheça evidentemente que o bem e o verdadeiro aí se encontram". ${ }^{16}$

Para Kant a liberdade reside na vontade sendo que esta "é uma espécie de causalidade dos seres vivos, enquanto racionais, a liberdade seria a propriedade desta causalidade, pela qual ela pode ser eficiente, independentemente de coisas estranhas que a determinem; assim como necessidade natural é a propriedade da causalidade de todos os seres irracionais de serem determinados à atividade pela influência de coisas estranhas. ${ }^{17}$

Kant ainda se manifesta aprofundando seu pensamento quando diz que a liberdade deve estar subordinada as leis imutáveis, ainda que de uma espécie particular; pois, de outro modo uma vontade livre seria um absurdo. ${ }^{18}$ (KANT, 1974, p. 243).

Kant relaciona liberdade com autonomia, afirma ser um direito do indivíduo em criar e observar suas próprias regras na medida de sua racionalidade. A liberdade está atrelada, em consonância a observância moral. Na atualidade a liberdade é um assunto recorrente que muito preocupa o homem, a necessidade de ser livre é algo que lhe é intrínseco, contudo suas ações devem ser guiadas pela ética e a moral.

\footnotetext{
${ }^{15}$ STOCO, Rui. Tratado de responsabilidade civil: doutrina e jurisprudência. 7 ed.. São Paulo Editora Revista dos Tribunais, 2007.

${ }^{16}$ DESCARTES, Reneé. Discurso sobre o Método. São Paulo: Atena, 1971

${ }^{17}$ KANT, Immanuel. Fundamentação da Metafísica dos costumes. Tradução de Valério Rohden. São Paulo: Abril cultural, 1974, p. 243.

${ }^{18}$ KANT, op. cit. 243.
} 
A liberdade para Kant é a essência do conceito de justiça e leciona que:

(...) a Justiça está relacionado ao agir de forma a conviver com a liberdade dos outros. Agir, assim, é atuar de forma justa. Injusto é a ação do outro que me impede de praticar minha liberdade. Daí pode-se concluir que tudo que impede a liberdade é injusto e tudo que afasta o obstáculo à liberdade é justo. A coação que alguém exerce contra a ação justa de outro é um obstáculo à liberdade. Assim, como a liberdade é o bem maior, o obstáculo ao obstáculo à liberdade é critério para definir o que é justo. "Uma ação é justa quando, por meio dela, ou segundo sua máxima, a liberdade do arbítrio de um pode continuar com a liberdade de qualquer outro segundo uma lei universal" 19

A liberdade é um dos pilares da ética juntamente com outros dois que correspondem a justiça e a solidariedade. O justo segundo o pensamento acima epigrafado consiste em reconhecer um ato como sendo justo a partir do reconhecimento de leis universais, as quais após incansável reflexão há o reconhecimento universal de sua aplicabilidade considerando o ideal de conduta. Pode-se assim descrever justiça a partir da colaboração doutrinaria de Franser:

(...) a justiça requer arranjos sociais que permitam a todos os membros (adultos) da sociedade interagir entre si como pares. São necessárias pelo menos duas condições para que a paridade participativa seja possível. Primeiro, deve haver uma distribuição de recursos materiais que garanta a independência e "vos" dos participantes. (...) a segunda condição requer que os padrões institucionalizados de valor cultural exprimam igual respeito por todos os participantes e garantam iguais oportunidades para alcançar a consideração $\operatorname{social}^{20}$ (FRASER, 2002, p. 13).

Considerando o terceiro pilar da ética, a solidariedade, é possível transcrever seu significado a partir do pensamento de Meirelles onde o autor aduz que solidariedade e a partilha dos encargos de forma a trazer a justiça social e distributiva, razão pela qual tem sido acolhida pelos Estados modernos. ${ }^{21}$

Para Duguit os direitos do indivíduo só existem a partir do momento que o mesmo integra uma sociedade organizada, o individuo ao viver isolado não possui qualquer direito, só os tem a partir do momento que passa a integrar um grupo, os direitos decorrem do compartilhamento de oportunidades. ${ }^{22}$

\footnotetext{
${ }^{19}$ KANT, Immanuel. A metafísica dos costumes. A doutrina do direito e a doutrina da virtude. Trad. Edson Bini. Bauru: EDIPRO, 2003, p. 407.

${ }^{20}$ FRASER, Nancy. Reconhecimento sem Ética?. In.: Revista Lua Nova, São Paulo. n.70. pp. 101-138. $2007 \mathrm{a}$.

${ }^{21}$ MEIRELLES, Hely Lopes. Direito administrativo brasileiro. 38 Ed., Editora Malheiros. 2011, p. 717

22 DUGUIT, Traité de Droit Constitucionnel, Tomo I, $3^{a}$ edição, Paris: A. Fontemoing Éditeurs, 1927, p. 212 apud FARIAS, José Fernando de Castro. A origem do direito da solidariedade. Rio de Janeiro: Renovar, 1998.
} 
O posicionamento doutrinário de Duguit é complementado por Habermas, que assim diz: "somente podem pretender validade legítima as leis jurídicas capazes de encontrar o assentimento de todos os parceiros do direito, num processo jurídico de normatização discursiva." 23

Em contraponto, Gurvitch afirma ser o direito social um direito independente de comunhão, que integra objetivamente cada totalidade trazendo valor positivo extratemporal desprendendo-se diretamente do todo de maneira que cada individuo usufrua do direito posto à coletividade. ${ }^{24}$

A ética, ou a falta dela, acompanha o homem em todos os seus relacionamentos. Contudo a observância dos preceitos éticos é essencial para o alcance de uma sociedade livre, justa e solidaria, princípios basilares do ordenamento jurídico brasileiro o qual surgiu dos anseios de um povo levando-se em consideração a cultura e os valores.

A consciência ética do cidadão promove o bem estar social e a importância do individuo ético pertencente a essa sociedade dando legitimidade e justiça aos interesses do homem e da sociedade.

\section{A ÉTICA E A MODERNIDADE}

A modernidade representa todos as épocas que um dia quebraram velhos paradigmas sob a promessa de algo inovador e melhor do que até então a humanidade conhecia, todas as épocas já significaram inovações no momento de sua descoberta. Segundo afirma Habermas:

O conceito de modernização refere-se a um conjunto de processos cumulativos e de reforço mútuo: à formação de capital e mobilização de recursos; ao desenvolvimento das forças produtivas e ao aumento da produtividade do trabalho; ao estabelecimento do poder político centralizado e à formação de identidades nacionais; à expansão dos direitos de participação política, das formas urbanas de vida e da formação escolar formal e, à secularização de valores e normas. $^{25}$

\footnotetext{
${ }^{23}$ HABERMAS, J. Direito e moral. Tradução Sandra Lippert. Lisboa: Instituto Piaget, 1999.

24 GURVITCH. Georges. L'Idée du Droit Social. Notion et Système du Droit Social. Histoire Doctrinale Depuis le XVIIème Siècle Jusqu'a la Fin du XIXème Siècle. Paris. Librarie du Recueil Sirey, 1931.pp. 1516apud FARIAS, José Fernando de Castro. A origem do direito da solidariedade. Rio de Janeiro: Renovar, 1998.

${ }^{25}$ HABERMAS, J. O discurso filosófico da modernidade. Tradução Luiz Sérgio Repa e Rodnei Nascimento. $1^{a}$ ed., $2^{a}$ tir. São Paulo: Martins Fontes, 2002. p. 05.
} 
Ao surgir o novo, a modernidade por assim dizer implica no abandono de certas tradições até então válidas para recepcionar um pensamento que melhor se apresente. $\mathrm{O}$ Bauman define Modernidade como um período histórico que começou na Europa Ocidental no século XVII com uma série de transformações sócio-estruturais e intelectuais profundas e atingiu sua maturidade primeiramente como projeto cultural, com o avanço do Iluminismo e depois como forma de vida socialmente consumada, com o desenvolvimento da sociedade industrial. ${ }^{26}$ (BAUMAN, 1999b, p. 299-300)

A Modernidade se justifica pela necessidade de reavaliar de forma crítica a tradição e concluindo por sua obsolescência rejeitá-la abrindo caminho à experimentação, mesmo que de alguma forma algum resquício de tradição ainda subsista. Modernidade é sinônimo de dinamismo que impulsiona uma constante mudança, sem cessar. Questionar as suas próprias conquistas e a incansável busca por inovações são características marcantes da modernidade. No limiar da era moderna, três grandes eventos lhe determinam o seu caráter: a descoberta da América, com uma nova visão de mundo, a Reforma na Igreja e a invenção do telescópio, que permitiu o desenvolvimento de uma nova ciência ${ }^{27}$.

Modernidade é sinônimo de sociedade moderna ou civilização industrial e está associada a um conjunto de atitudes perante o mundo, como a ideia de que o mundo é passível de transformação pela intervenção humana ${ }^{28}$.

A moral no decorrer histórico apresentou-se de formas distintas. Na primeira versão seguia preceitos teológicos, na segunda é a moral moderna sendo chamada de laica moralista; e a terceira é chamada de pós moralista. ${ }^{29}$

A moral pós moralista, a que interessa para esse estudo, segundo a visão de Morin, está em crise, há uma desordem própria onde uma modernidade substitui outra, e isso pode ser observado.

Quando não mais existe valores teológicos em razão de terem sido substituídos pela razão, pelo progresso e pela técnica. Os valores sociais a serem seguidos foram extintos e da mesma maneira a consciência moral que determina o que deve ser feito. $\mathrm{O}$

\footnotetext{
${ }^{26}$ BAUMAN, Z., Modernidade e ambivalência. Tradução Marcus Penchel. Rio de Janeiro: Jorge Zahar, 1999.

${ }^{27}$ HABEBERMAS, op. cit., p. 05.

${ }^{28}$ GIDDENS, A.; PIERSON, C., Conversas com Anthony Giddens: o sentido da modernidade. Rio de Janeiro: FGV, p. 73

${ }^{29}$ LIPOVETSKY. G. Metamorfoses da cultura liberal. Porto Alegre: Sulina, 2004.
} 
sentido da responsabilidade encolheu, bem como o sentido da solidariedade enfraqueceu. $^{30}$

Sendo a moral um elemento importante da ética, a modernidade hoje vivencia e a que está por vir sempre será sempre um desafio para os signos da ética na medida que obriga o homem a repensar o seu papel na sociedade na busca do bem estar próprio e coletivo.

A cultura muda lentamente e conecta-se a realidade humana de forma fluída gerando raízes até que novos ideais a impulse a novamente. É verdade que a modernidade promoveu a evolução e as maiores conquistas humanas, sendo portanto, a democratização dos direitos humanos a sua mais significativa conquista. É notável ao longo dos séculos que o avanço técnico-científico possibilitou a melhoria do bem estar social.

No entanto, mesmo com todos estes avanços houve, por conseguinte, uma estruturação da vida humana que nem sempre trouxe uma realização profunda do existir sendo esta característica uma reflexão emergente nos dias atuais. ${ }^{31}$

Em uma sociedade que busca o engajamento mutuo em prol do desenvolvimento e do bem estar não pode estar alheio ao que preconiza o doutrinador Freire que assim leciona: "a mudança da percepção da realidade, que antes era vista como algo imutável, significa para os indivíduos vê-la como realmente é: uma realidade histórico-cultural, humana, criada pelos homens e que pode ser transformada por eles." ${ }^{32}$

Freire aduz ainda que o homem é capaz de alterar sua realidade: "tentar a conscientização dos indivíduos com quem se trabalha, enquanto com eles também se conscientiza, este e não outro, nos parece ser o papel do ser humano que optou pela mudança",33

A título de exemplificação de como a dinâmica de uma modernidade impacta no cotidiano do homem, segue a lição de Giddens:

As consequências da modernidade, por exemplo, se lê que o oposto de
"amigo" já não é mais "inimigo", nem mesmo "estranho"; ao invés disto é
"conhecido", "colega", ou "alguém que não conheço". Acompanhando esta
transição, a honra é substituída pela lealdade que não tem outro apoio a não ser
o afeto pessoal, e a sinceridade é substituída pelo que podemos chamar de
autenticidade: a exigência que o outro seja aberto e bem-intencionado. Um
amigo não é alguém que sempre fala a verdade, mas alguém que protege o
bem-estar emocional do outro. O "bom amigo" - alguém cuja benevolência é

\footnotetext{
${ }^{30}$ MORIN, E. O método 6: ética. Porto Alegre: Sulina, 2005.

${ }^{31}$ MORIN. op. cit.

32 FREIRE, Paulo. Educação e mudança. 12a Edição. Paz e Terra. Rio de Janeiro, 1979.

${ }^{33}$ Idem.
} 
disponível mesmo em tempos difíceis - é o substituto nos dias de hoje para o "honorável companheiro"34.

Não é de difícil constatação de que os mesmos relacionamentos passam a ter conotações diferentes ao longo do tempo, nos dizeres de Giddens o relacionamento que antes era muito próximo ou muito distante passa a ser não tão próximo e também não muito distante, e o resultado dessa perspectiva, que hoje tem uma razão de ser, somente com o passar do tempo o homem descobrirá o que realmente será e talvez não signifique algo que possa se transformar em uma tradição.

Muito atual e significativo é o comportamento responsável, a responsabilidade em razão do agir condiciona a reflexão e ao questionamento: para que devo fazer ou não fazer algo? A responsabilidade é a essência do direito, onde o direito é a representação positivada dos valores morais e culturais de um povo, é a concretização do exercício da cidadania que por sua vez é guiado pela ética.

A ética está intrínseca no nosso direito pátrio em seus primeiros artigos conforme prescreve o artigo $3^{\circ}$ da Constituição da República de 1988: constituem objetivos fundamentais da República Federativa do Brasil, inciso I - construir uma sociedade livre, justa e solidária; sendo a liberdade, a justiça e a solidariedade os pilares da ética.

Hans Jonas acredita que "O homem livre assume para si a responsabilidade, que aguardava seu amo, e se submete à sua exigência. A mais sublime e desmedida liberdade do eu conduz ao mais exigente e inclemente dos deveres." 35

Kuiava afirma que a teoria de Hans Jonas tem como princípio central da ética a responsabilidade, e essa postura comportamental responsável garantirá a sobrevivência das gerações futuras, ou seja, com o tempo vindouro, compatível com a era da ciência e da tecnologia, cuja responsabilidade passa a ser o alicerce, o princípio orientador para as decisões que possam interferir nas diferentes formas de vida. ${ }^{36}$

A responsabilidade pousa soberana sob o manto da racionalidade e deve observar dois aspectos em específico que consistem no dever, o homem deve estar consciente de suas obrigações e ser capaz de auto influenciar-se, dominar sua própria vontade, onde seu dever deverá sempre prevalecer e suas ações determinada por este dever.

\footnotetext{
${ }^{34}$ GIDDENS, Anthony. As consequências da modernidade. Tradução: Raul Fiker. São Paulo: Editora Unesp, 1991, p. 134

35 JONAS, Hans (2006) O Princípio Responsabilidade: Ensaio de uma Ética para a civilização tecnológica. RJ: Contraponto / PUC-RIO.

${ }^{36}$ KUIAVA, Evaldo Antonio. A responsabilidade como princípio ético em H. Jonas e E. Levinas: uma aproximação. Veritas, Porto Alegre, v. 51, n. 2, p. 56, jun. 2006.
} 
Para Beck, a geração presente já está vivendo a era dos efeitos colaterais e carrega consigo a "ambivalência da modernidade" trabalhada em Bauman. É nessa revelação que o autor vai dizer que o não saber, a perda de certezas, a insegurança em relação ao futuro, a tomada de decisão e a negociação são os meios da modernização reflexiva. Dito de outro modo, é da dúvida da ameaça e da percepção geral de ameaça que surge o interesse em refletir sobre ela, de preveni-la, comunicá-la e eliminá-la. ${ }^{37}$

Segundo Beck o próprio progresso da modernização destrói e modifica uma modernidade para o nascimento de outra, já que todos estão "cegos e surdos a seus efeitos e ameaças onde a própria radicalização da modernidade desenha os contornos da modernização reflexiva. ${ }^{38}$

Dia após dia o mundo transforma-se, desde as mais imperceptíveis mudanças até as mais visíveis e impactantes, Beck preocupa-se com as mudanças sutis, pois essas passam despercebidas a ponto de não induzir o homem a reflexão e tão pouco fazê-lo ter consciência dos impactos futuros uma vez que são incorporadas na rotina diária como única opção possível.

A ética como instrumento balizador do comportamento humano em prol do bem estar individual e coletivo é caracterizada pelo paradoxo entre progresso e a ruptura das tradições.

Em um contexto de interação complexa que hoje a sociedade está inserida, a reflexão sobre o que vem a ser ético é fundamental para o alcance dos ideais de cidadania. Os esforços no sentido de positivar valores morais e estabelecer coesão no sistema jurídico vigente serão ineficazes se a cidadania não estiver de fato à disposição.

Os componentes do ciclo virtuoso depende da manutenção dos valores éticos, da constante reflexão sobre os valores morais e culturais, da codificação legal para a promoção de bem estar almejado pela sociedade, da manutenção da ética mesmo diante das novas modernidades.

A reflexão buscando a transformação positiva, em qualquer modernidade, na de hoje e na futura, é e será primordial o olhar atento no mesmo compasso que o principal

\footnotetext{
${ }^{37}$ BECK, Ulrich. Autodissolução e autorrisco da sociedade industrial: o que isso significa? In: BECK, Ulrich; GIDDENS, Anthony; LASCH, Scott. Modernização reflexiva: política, tradição e estética na ordem social moderna. Trad. de Magda Lopes. 2. ed. São Paulo: Edunesp, 2012. p. 86, 207.

${ }^{38} \mathrm{BECK}$, ULRICH, A reinvenção da política: rumo a uma teoria da modernização reflexiva. In: GIDDENS, A.; BECK, U.; SCOTT, L. (Orgs.). Modernização reflexiva: política, tradição e estética na ordem social moderna. São Paulo: UNESP. 1997
} 
objetivo da humanidade é viver plenamente com respeito a sua individualidade e de seus pares.

\section{A GLOBALIZAÇÃO E SEUS REFLEXOS NA ÉTICA}

Uma das faces da globalização se traduz num processo social que define uma relação entre os países e as pessoas do mundo inteiro, sendo que através deste processo governantes e empresas trocam informações, pactuam acordos financeiros e comerciais como também disseminam aspectos culturais nos mais diversos territórios. ${ }^{39}$

A globalização está intimamente ligada a interconectividade entre as nações, os povos em geral e as organizações pelo mundo. Essas relações podem ter diversos motivos, sendo que o seu resultado é na verdade a interdependência entre ambientes humanos e físicos segmentados geograficamente. ${ }^{40}$

As novas tecnologias trazidas pela globalização trouxe uma dimensão jamais vista na sociedade, além de novas formas produtivas eliminou fronteiras e mesclou culturas contextualizando valores fomentando o surgimento de outros tantos. Houve uma realidade forjada na tradição que precisou ser relativizada diante de tantas hipóteses até então desconhecidas

Canclini ressalta a importância da convivência da cultura global com as características das culturas locais: Surge, então, a pergunta sobre se seremos capazes de construir uma ordem intercultural globalizada na qual as dimensões sociais, econômicas, políticas e culturais se reorganizem a fim de que aprendamos a descobrir o valor do diferente, a reduzir a desigualdade que converte as diferenças em ameaças irritantes e a gerar conexões construtivas à distância ${ }^{41}$.

Dupas alerta sobre "o deslumbramento diante da novidade tecnológica e a ausência total de valores éticos que definam limites e rumos poderão estar incubando

\footnotetext{
${ }^{39}$ CERUTTI. Luiza e CITOLIN, Michele. A atuação da globalização sobre a sociedade atual. Colégio Mãe de Deus - Revista Eletrônica. V. 1, $\mathrm{n}^{\mathbf{0}}$ 1, Setembro, 2010. Disponível em: file://C:/Users/maquina02/Downloads/revista\%20eletronica.pdf. Acessado em: 15/02/2016.

${ }^{40}$ MADEIRA, Adriana Beatriz. Internacionalização do Varejo: Um estudo com empresas brasileiras por meio de análise de conteúdo. Tese de Doutorado apresentada no curso de Administração da Universidade de São Paulo. São Paulo, 2009, p. 19. Disponível em: file://C:/Users/maquina02/Downloads/Tese_Adriana_Beatriz.pdf. Acessado em: 15/02/2016.

${ }^{41}$ Canclini, N. G. (2007). Diferentes, desiguais e desconectados: mapas da interculturalidade. Tradução Luiz Sérgio Henriques. 2a ed. Rio de Janeiro, Brasil: Editora UFRJ, p. 268
} 
tanto novos deuses, que conduzirão a humanidade à sua redenção, como serpentes cujos venenos ameaçarão sua própria sobrevivência". ${ }^{42}$

A observação de Dupas é severa e profundamente voltada para o pessimismo, como já observou-se em outras eras as invenções de outrora também causaram espanto e indagações, foram refutadas, seus inventores perseguidos, massacrados; e, somente mais adiante a humanidade passou a valorizar as obras e seus inventores. Não se sabe o que esta por vir, mas o dever da humanidade é refletir sobre, pensar com a mais ampla perspectiva, utilizar-se de seus recursos de forma plena e quem sabe reinventar a sua utilidade.

A globalização sem solidariedade seria uma máquina de moer as verdadeiras liberdades. Uma verdadeira ameaça à democracia. (...) Para que a globalização possa representar uma chance para a humanidade, ela deve ser posta a serviço da pessoa humana. Talvez a globalização seja o novo nome do desenvolvimento. (...) O desenvolvimento de todo homem e do homem todo. ${ }^{43}$

A consolidação da globalização atual, proporcionou uma integração que “aconteceu de tal forma que tornou comum a expressão 'aldeia global'. O termo 'aldeia' faz referência a algo pequeno," local onde tudo está próximo, o que remete automaticamente a ideia de que aduzida integração no meio técnico-informacional tornou o planeta metaforicamente menor. ${ }^{44}$

Nestes sentido, importante colacionar o posicionamento que segue:

A globalização é uma tendência internacional do capitalismo que, juntamente com o projeto neoliberal, impõe aos países periféricos a economia de mercado global sem restrições, a competição ilimitada e a minimização do Estado na área econômica e social. ${ }^{45}$

O advento de um sistema econômico global, o crescimento constante de economia de serviço, dirigida pela internet, de mercados de alta tecnologia e baseados no conhecimento das redes e dimensões da economia do valor, fazendo com que haja a necessidade de refletir sobre esses novos comportamentos. ${ }^{46}$ "Se é isso o que a

\footnotetext{
${ }^{42}$ Dupas, G. Ética e poder na sociedade da informação: de como a autonomia das novas tecnologias obriga a rever o mito do progresso (3a ed.). São Paulo, Brasil: Editora Unesp. 2011. P 103

${ }^{43}$ LONGCHAMP, Albert. Globalização: o novo nome do desenvolvimento? In: Globalização e fé. Bauru: EDUSC, 2000. p. 132

44 PENA, Rodolfo Alves. Globalização. Brasil Escola. 2016. Disponível em: http://m.brasilescola.uol.com.br/geografia/globalizacao.htm. Acessado em: 16/02/2016.

${ }^{45}$ OLIVEIRA, J.F., LIBÂNEO, J.C. A Educação Escolar: sociedade contemporânea. In: Revista Fragmentos de Cultura, v. 8, n.3, p.597-612, Goiânia: IFITEG, 1998.

${ }^{46}$ Idem, cit. 3, p. 20.
} 
autoconsciência pós-moderna nos deixou claro, essa nova clareza pode andar um longo caminho para fazer o balanço do golpe que deu a nossas certezas acarinhadas e desanuviadas". ${ }^{47}$

O autor claramente demonstra seu temor sobre o que está por vir, já possui uma ideia pré-conceituada sobre o futuro, o desaparecimento das certezas, das crenças e da habitual reprodução de ideias antigas. Porém suas dúvidas também não correspondem a certezas, são dúvidas hipóteses e o futuro é regido pelo risco, e nem todos os riscos necessariamente significarão algo ruim, se assim fosse o homem estaria vivendo como a séculos remotos vivia, não teria aceitado o risco de progredir.

Na lição de Fensterseifer, se referindo as ameaças da modernidade atual, sugere que:

\begin{abstract}
A própria existência (e não apenas a dignidade) humana está ameaçada pelos padrões tecnológicos contemporâneos. (...) na grande maioria das vezes a ciência está a serviço de interesses puramente econômicos, o que, como refere, coloca o ser humano como, dentre todas as espécies que já habitaram o Planeta Terra, a mais destrutiva e ameaçadora. ${ }^{48}$
\end{abstract}

Seu olhar instiga a reflexão, é notável a instabilidade social que a globalização inseriu, a modernidade que sobrepõe outra traz desconforto e resistências, mas também traz esperança, resiliência e necessidade de adaptações e principalmente a metamorfose da moral e da ética, as quais são forçadas a reflexão de forma proporcional que a nova interação exige a manutenção pela busca pelo bem estar e pelo que é bom.

Freire, no entanto, possui uma concepção próxima do que pensa Beck pois afirma que a flexibilização das normas atinge todas as hierarquias, da Constituição Federal às leis infraconstitucionais. No direito brasileiro constitucional é notório o retalhamento da Constituição e o esvaziamento dos direitos fundamentais de forma tão nítida quanto assustadora. ${ }^{49}$

Diante da amplitude da globalização, uma vez que esta interfere em praticamente todos os aspectos da vida humana se estendendo desde um simples costume local até aspectos políticos e econômicos e sendo a ideia do autor correta, há um claro e

\footnotetext{
${ }^{47}$ BECK, UIrich apud BAUMAN, Zygmunt. Ética Pós-moderna, tradução João Resende Costa, São Paulo: Paulus, 1997, p. 253.

${ }^{48}$ FENSTERSEIFER, Tiago. Direitos fundamentais e proteção do meio ambiente: a dimensão ecológica da dignidade humana no marco jurídico constitucional do estado sócio-ambiental de direito. Porto Alegre: Livraria do Advogado, 2008. p. 58.

${ }^{49}$ FREIRE JÚNIOR, Américo Bedê. 2001 Uma Constituição no Espaço, artigo in Revista Tributária e de Finanças Públicas, n. 40. setembro/outubro de 2001, p. 250.
} 
progressivo desrespeito a cidadania. O exercício da cidadania depende da proteção e alcance dos direitos fundamentais.

Oscar Vilhena Vieira aduz "que os sistemas constitucionais vêm sendo fortemente pressionados por diversas demandas impostas por um cenário internacional em rápida reconfiguração" 50 .

As mudanças e tendências do constitucionalismo pós-moderno não podem distanciar-se da proteção internacional aos direitos do homem, como meio de conter práticas abusivas dos Estados, de grupos intermediários, do poder econômico paralelo e das descobertas científicas contrárias à dignidade da pessoa humana ${ }^{51}$.

Considerar válida a readaptação das normas internas às condições externas põe em discussão a soberania estatal é na verdade a redefinição da soberania estatal perante o movimento global, o que pressupõe pensar qual é o limite do Estado, até que ponto chegarão as reivindicações que emergem dos novos paradigmas trazidos pela globalização. ${ }^{52}$

É fato que a globalização trouxe mudanças salvaguardar os direitos básicos do cidadão, apresentando em seu bojo regras definidas de liberdade, justiça e solidariedade proporcionam eficientemente as condições para o pousar manso da ética.

\section{CONSIDERAÇÕES FINAIS}

A modernidade possui duas faces, uma delas representada pelas resistências em razão de conformação com as condições já existentes, o progresso gera inseguranças, incertezas e a princípio não parece bom, a outra face é o entusiasmo, o movimento a transformação do velho em novo e uma redefinição conceitos. Induz a novas perspectivas e experimentações nunca antes oportunizadas.

A ética possui uma essência construída ao longo dos séculos, sua tradição foi forjada no íntimo do ser humano. É natural que o homem persiga seu o bem estar ao passo que entendeu que seu bem estar está diretamente vinculado ao bem estar da coletividade.

\footnotetext{
50 VIEIRA, Oscar Vilhena. A Globalização e o Direito. Disponível em: http://www.dhnet.org.br/direitos/militantes/oscarvilhena/vilhena_unidir.html. Acessado em: 23/02/2016.

${ }^{51}$ LEÃO, Adroaldo. Globalização e o Constitucionalismo Pós-Moderno, in Adroaldo Leão e Rodolfo Pamplona Filho (coord.), Globalização e Direito, 2004.

52 OLIVEIRA, José Anselmo. Soberania Estatal na Perspectiva da Globalização. Revista do Tribunal de Justiça do Estado de Sergipe. Aracaju: Liceu, v. 24, 2000, p. 27.
} 
E nesse contexto a elegibilidade dos valores que compõe a ética a nível coletivo são aqueles valores universais, e estes alimentam a ética e sendo mutáveis condicionam o estudo da ética em conformidade com o seu contexto histórico.

A sociedade evolui e seu progresso produz fragmentação e complexidade e em muitos casos o seu progresso é a razão de existir da própria decadência, em todas as modernidades foi assim, a aflição é que em nenhuma era a velocidade das mudanças se apresentou como na atual revolução, se assim puder ser chamado o histórico que vivemos.

A quarta revolução, marcada pela globalização, trouxe efeitos negativos perceptíveis já nas primeiras décadas e no ritmo que esse movimento global acontece os estudos científicos no sentido de neutralizar esses efeitos ou com possíveis soluções a nova problemática não acontecem na mesma velocidade. É fato o progresso é inevitável e o estudo responsável sobre a ética também.

O que de fato ocorre no mundo com o surgimento da tecnologia de informação é que apesar do livre acesso a um imensurável número de informações, em vez de uma intensa dedicação a resolver as questões há uma crescente disseminação de informações enganosas e distorcidas, e isso se relaciona com a ética na medida que se aplicam princípios éticos baseados em falácias.

O futuro é incerto, mas administrar certos riscos e ter sempre em mente a responsabilidade com o bem estar com as próximas gerações é um ato solidário. A modernidade não pode estar desacoplada das preocupações com a ética, e os malefícios e benefícios de uma modernidade precisam atender determinados preceitos éticos imutáveis, como por exemplo, o que é bom para o homem e este depende da conotação de valor que o define dada pela humanidade em determinado tempo.

\section{REFERÊNCIAS}

ACQUAVIVA, Marcus Cláudio. Notas Introdutórias à Ética Jurídica. São Paulo: Desafio Cultural, 2002.p. 27

ARISTÓTELES, Ética a Nicômaco. Pietro Nassetti (tradução). Martin Claret, SP, 2007.

BAUMAN, Z., Modernidade e ambivalência. Tradução Marcus Penchel. Rio de Janeiro: Jorge Zahar, 1999.

BECK, UIrich apud BAUMAN, Zygmunt. Ética Pós-moderna, tradução João Resende Costa, São Paulo: Paulus, 1997, p. 253. 
BECK, ULRICH, A reinvenção da política: rumo a uma teoria da modernização reflexiva. In: GIDDENS, A.; BECK, U.; SCOTT, L. (Orgs.). Modernização reflexiva: política, tradição e estética na ordem social moderna. São Paulo: UNESP. 1997

BECK, Ulrich. Autodissolução e autorrisco da sociedade industrial: o que isso significa? In: BECK, Ulrich; GIDDENS, Anthony; LASCH, Scott. Modernização reflexiva: política, tradição e estética na ordem social moderna. Trad. de Magda Lopes. 2. ed. São Paulo: Edunesp, 2012. p. 86, 207.

Canclini, N. G. (2007). Diferentes, desiguais e desconectados: mapas da interculturalidade. Tradução Luiz Sérgio Henriques. 2a ed. Rio de Janeiro, Brasil: Editora UFRJ, p. 268

CERUTTI. Luiza e CITOLIN, Michele. A atuação da globalização sobre a sociedade atual. Colégio Mãe de Deus - Revista Eletrônica. V. 1, nº 1, Setembro, 2010. Disponível em: file:///C:/Users/maquina02/Downloads/revista\%20eletronica.pdf. Acessado em: 15/02/2016.

CHAUÍ, M. Convite à Filosofia. São Paulo: Ática, 1998.

CORTELLA, M. S. Qual é a tua obra? Inquietações, propositivas sobre gestão, liderança e ética. Petrópolis: Vozes, 2009. p. 102

DESCARTES, Reneé. Discurso sobre o Método. São Paulo: Atena, 1971

DUGUIT, Traité de Droit Constitucionnel, Tomo I, $3^{\text {a }}$ edição, Paris: A. Fontemoing Éditeurs, 1927, p. 212 apud FARIAS, José Fernando de Castro. A origem do direito da solidariedade. Rio de Janeiro: Renovar, 1998.

Dupas, G. Ética e poder na sociedade da informação: de como a autonomia das novas tecnologias obriga a rever o mito do progresso (3a ed.). São Paulo, Brasil: Editora Unesp. 2011. P 103

FENSTERSEIFER, Tiago. Direitos fundamentais e proteção do meio ambiente: a dimensão ecológica da dignidade humana no marco jurídico constitucional do estado sócio-ambiental de direito. Porto Alegre: Livraria do Advogado, 2008. p. 58.

FRASER, Nancy. Reconhecimento sem Ética?. In.: Revista Lua Nova, São Paulo. n.70. pp. 101-138. 2007a.

FREIRE JÚNIOR, Américo Bedê. 2001 Uma Constituição no Espaço, artigo in Revista Tributária e de Finanças Públicas, n. 40. setembro/outubro de 2001, p. 250.

FREIRE, Paulo. Educação e mudança. 12ª Edição. Paz e Terra. Rio de Janeiro, 1979.

GIDDENS, A.; PIERSON, C., Conversas com Anthony Giddens: o sentido da modernidade. Rio de Janeiro: FGV, p. 73

GIDDENS, Anthony. As consequências da modernidade. Tradução: Raul Fiker. São Paulo: Editora Unesp, 1991, p. 134 
GOUVÊA, Ricardo Quadros. Ética e Cidadania: A busca humana por valores solidários. In: Um olhar sobre a ética. São Paulo: Editora Mackenzie, 2002. p. 15.

GURVITCH. Georges. L'Idée du Droit Social. Notion et Système du Droit Social. Histoire Doctrinale Depuis le XVIIème Siècle Jusqu'a la Fin du XIXème Siècle. Paris. Librarie du Recueil Sirey, 1931.pp. 15-16apud FARIAS, José Fernando de Castro. A origem do direito da solidariedade. Rio de Janeiro: Renovar, 1998.

HABERMAS, J. Direito e moral. Tradução Sandra Lippert. Lisboa: Instituto Piaget, 1999.

HABERMAS, J. O discurso filosófico da modernidade. Tradução Luiz Sérgio Repa e Rodnei Nascimento. $1^{\mathrm{a}}$ ed., $2^{\mathrm{a}}$ tir. São Paulo: Martins Fontes, 2002. p. 05.

JONAS, Hans (2006) O Princípio Responsabilidade: Ensaio de uma Ética para a civilização tecnológica. RJ: Contraponto / PUC-RIO.

KANT, Immanuel. A metafísica dos costumes. A doutrina do direito e a doutrina da virtude. Trad. Edson Bini. Bauru: EDIPRO, 2003, p. 407.

KANT, Immanuel. Fundamentação da Metafísica dos costumes. Tradução de Valério Rohden. São Paulo: Abril cultural, 1974, p. 243.

KUIAVA, Evaldo Antonio. A responsabilidade como princípio ético em H. Jonas e E. Levinas: uma aproximação. Veritas, Porto Alegre, v. 51, n. 2, p. 56, jun. 2006.

LEÃO, Adroaldo. Globalização e o Constitucionalismo Pós-Moderno, in Adroaldo Leão e Rodolfo Pamplona Filho (coord.), Globalização e Direito, 2004.

LIPOVETSKY. G. Metamorfoses da cultura liberal. Porto Alegre: Sulina, 2004.

LONGCHAMP, Albert. Globalização: o novo nome do desenvolvimento? In: Globalização e fé. Bauru: EDUSC, 2000. p. 132

LUSTOZA, Helton Kramer. A crise da ética na sociedade brasileira.. Revista Juridica, [S.1.], v. 1, n. 30, p. 271-283, maio 2013. ISSN 2316-753X. Disponível em: <http://revista.unicuritiba.edu.br/index.php/RevJur/article/view/563/435>. Acesso em: 17 abr. 2020. doi:http://dx.doi.org/10.21902/revistajur.2316-753X.v1i30.563.

MADEIRA, Adriana Beatriz. Internacionalização do Varejo: Um estudo com empresas brasileiras por meio de análise de conteúdo. Tese de Doutorado apresentada no curso de Administração da Universidade de São Paulo. São Paulo, 2009, p. 19. Disponível em: file:///C:/Users/maquina02/Downloads/Tese_Adriana_Beatriz.pdf. Acessado em: 15/02/2016.

MATOS, O. C. F. A escola de Frankfurt: luzes e sombras do iluminismo. São Paulo: Editora Moderna, 1993

MEIRELLES, Hely Lopes. Direito administrativo brasileiro. 38 Ed., Editora Malheiros. 2011, p. 717 
MORIN, E. O método 6: ética. Porto Alegre: Sulina, 2005.

OLIVEIRA, J.F., LIBÂNEO, J.C. A Educação Escolar: sociedade contemporânea. In: Revista Fragmentos de Cultura, v. 8, n.3, p.597-612, Goiânia: IFITEG, 1998.

OLIVEIRA, José Anselmo. Soberania Estatal na Perspectiva da Globalização. Revista do Tribunal de Justiça do Estado de Sergipe. Aracaju: Liceu, v. 24, 2000, p. 27.

PENA, Rodolfo Alves. Globalização. Brasil Escola. 2016. Disponível em: http://m.brasilescola.uol.com.br/geografia/globalizacao.htm. Acessado em: 16/02/2016.

PLATÃO, As Leis, 644b.

STOCO, Rui. Tratado de responsabilidade civil: doutrina e jurisprudência. 7 ed.. São Paulo Editora Revista dos Tribunais, 2007.

LUCCA, Newton De, Da ética Geral à ética Empresarial, São Paulo: Quartier Latin, 2009.

VÁZQUES, Adolfo Sánchez. Ética. Civilização Brasileira, 15 ed., 1997.p.231.

VIEIRA, Oscar Vilhena. A Globalização e o Direito. Disponível em: http://www.dhnet.org.br/direitos/militantes/oscarvilhena/vilhena_unidir.html. Acessado em: 23/02/2016. 